\title{
A quantitative study of chiasma terminalization in the grasshopper Chorthippus jucundus
}

J. L. Santos,

G. Ciprés and

J. R. Lacadena
Departamento de Genética. Facultad de Ciencias Biológicas, Universidad Complutense, 28040 Madrid, Spain

The possible existence of chiasma terminalization in the grasshopper Chorthippus jucundus was tested in four males by means of comparisons between chiasma locations at diplotene and metaphase $I$ within $\mathbf{L}_{3}, \mathbf{M}_{4}$ and $\mathbf{M}_{5}$ bivalents. Diplotene cells were stained by a $\mathrm{C}$-banding technique to recognize heterochromatic regions, especially the centromeric ones, whereas metaphase I cells were stained by a silver staining technique that visualizes a core-like structure that extends through each homologous chromosome. The core is very pronounced at kinetochores and forms cross-shaped configurations at chiasmata. No evidence of chiasma terminalization has been found.

\section{INTRODUCTION}

Since Darlington (1929) defined chiasma terminalization as a progressive shift between diplotene and metaphase I of the first meiotic division in the distribution of chiasmata along the arms of paired chromosomes from their points of origin to more distal positions, many different approaches have been followed to test the existence of this phenomenon. These include: (i) careful measurements of chiasma positions in diplotene (Fox, 1973) or diakinesis bivalents (Hultén, 1974; Maudlin and Evans, 1980; Imai and Moriwaki, 1982); comparisons between chiasma distributions at diplotene and metaphase I cells of the same individual (Darlington 1929; Hearne and Huskins, 1935) or between recombination nodules at pachytene and chiasma locations at diakinesis (Holm and Rasmussen, 1983), (ii) analysis of labelling pattern in autoradiographs of $\mathrm{X}_{2}$-labelled diplotene bivalents (Jones, 1977), (iii) analysis of crossover exchanges between light and dark chromatids achieved by FPG staining after BrdU incorporation (Tease and Jones, 1978; Allen, 1979; Polani et al., 1979; Kanda and Kato, 1980), (iv) studies of chiasma movements using C-bands (Jones, 1978; Santos and Giráldez, 1978; Loidl, 1979; Mascarello, 1980; Orellana and Giráldez, 1981) or knobs as cytological markers (Maguire 1979, 1981).
The conclusions reached in the works mentioned above on the existence of chiasma terminalization appear to be contradictory (for more information see Jones, 1987 and Loidl, 1987) although the general opinion is that there is no movement of chiasmata during meiotic prophase. Nevertheless, the controversy remains open (see von Wettstein et al., 1984). At this point it is important to know whether or not chiasma terminalization is a general phenomenon since in conventional meiotic systems a certain degree of chiasma movement would invalidate any deductions concerning the control of chiasma distribution or any inferences about genetical recombination in different regions based on chiasma data (Jones, 1984).

In this work, we study the possible existence of chiasma terminalization in the grasshopper Chorthippus jucundus by means of a traditional design based on comparisons between chiasma locations at diplotene and metaphase I cells of the same individual but we have avoided the problem resulting from the condensed appearance of metaphase I bivalents that hinder the assignment of the exact position of chiasmata. This has been solved by means of a silver staining technique described previously (Santos et al., 1987) that visualizes a core-like structure that extends through the whole length of each homologous chromosome. It is especially pronounced at kinetochores and forms 
cross-shaped configurations at chiasmata. In these cross-shaped configurations it can be observed that this core is double, one per chromatid. In addition in many bivalents such configurations coincide with the inflexion points or constrictions observed in the external morphological contour of bivalents. In other cases they yield more information since, for instance, two cross-shaped configurations can be observed in metaphase I bivalents that would be assigned as monochiasmatic according to their external morphology.

\section{MATERIALS AND METHODS}

Adult males of $C$. jucundus were collected from a natural population at Puerto de la Morcuera (Madrid) in the summer of 1985. Testes of four males (numbers 6, 8, 3 and 20) were dissected into insect saline solution, fixed in $3: 1$ ethanol-glacial acetic acid and stored at $4^{\circ} \mathrm{C}$. Testis follicles were squashed in 45 per cent acetic acid, the cover-slips removed and the slides placed in absolute ethanol for at least 24 hours and air dried. The testes of each individual were divided in two portions. One portion was stained by means of a C-banding procedure described by Santos and Giráldez (1978) to score chiasma localization in diplotene cells, the other portion was stained by a silver nitrate technique described by Santos et al. (1987) to score chiasma localization in metaphase I cells.

The $C$. jucundus karyotype consists of three pairs of large submetacentric chromosomes $\left(\mathrm{L}_{1}-\right.$ $\mathrm{L}_{3}$ ), three pairs of large submetacentric chromosomes $\left(L_{1}-L_{3}\right)$, three pairs of acrocentric chromosomes $\left(\mathbf{M}_{4}-\mathbf{M}_{6}\right)$, two pairs of telocentric ones $\left(\mathbf{M}_{7}\right.$ and $\mathrm{S}_{8}$ ) and the acrocentric $\mathrm{X}$ chromosome (Santos, 1980). A detailed analysis was made of the $L_{3}$, $\mathbf{M}_{4}$ and $\mathbf{M}_{5}$ bivalents. All of them were drawn at diplotene and metaphase I from projected photographic negatives at a magnification of approximately $\times 3000$ for diplotene cells and $\times 4000$ for metaphase I cells. The position of the centromeres was clearly visualized in both meiotic stages and the position of each chiasma was measured using a calibrated map measurer that was driven along the whole bivalent in diplotene cells and the corelike structures visualized in metaphase I bivalents after silver staining. To overcome the problem of variation in absolute bivalent length between cells and meiotic phases, the position of each chiasma was recorded as the distance from the centromere to the chiasma measured in both homologues expressed as a percentage of the total length of two homologous in $\mathrm{M}_{4}$ and $\mathrm{M}_{5}$ bivalents and of each chromosome arm (long or short) in the case of the $\mathrm{L}_{3}$ bivalent.

To test for chiasma terminalization, comparisons of chiasma distributions in $\mathrm{L}_{3}, \mathrm{M}_{4}$ and $\mathbf{M}_{5}$ bivalents in diplotene and metaphase I cells within the same individual were carried out by means of contingency $\chi^{2}$ tests. In these comparisons, bivalents with different numbers of chiasmata have been considered separately, thus within $\mathrm{L}_{3}$ bivalent there are two main bivalent classes: $1: 1$ bivalents with one chiasma in each arm and $1: 2$ bivalents with one short and two long arm chiasmata. Although $2: 2$ and $1: 3$ bivalents were found, they were not considered for statistical purposes due to their low frequencies. Likewise, in $\mathrm{M}_{4}$ and $\mathrm{M}_{5}$ bivalents two classes with one and two chiasmata were established.

For $\chi^{2}$ tests, each chromosome or chromosome arm was divided into a series of intervals and the number of chiasmata observed in each interval at both meiotic stages was entered for each individual. Initially, and following Laurie and Jones (1981), bivalents were divided into intervals of equal length corresponding to 5 per cent of each chromosome or chromosome arm but for the purposes of a more general analysis and taking into account the different chiasma distributions shown by the bivalent classes, the bivalent intervals were grouped in such a way that they allowed a comparison among all individuals analyzed and that none of the expected values were less than five; however, this was not possible in all cases.

\section{RESULTS}

Giemsa C-banding applied to meiotic cells of the grasshopper C. jucundus revealed centromeric heterochromatin in all chromosomes. Telomeric heterochromatin was found only in chromosomes of medium and small size $\left(\mathbf{M}_{4}\right.$ to $\left.\mathrm{S}_{8}\right)$ and interstitial bands were located in the short arms of $\mathrm{L}_{2}$ and $\mathrm{L}_{3}$ bivalents that correspond to nucleolar organizer regions (Rufas et al., 1985).

The study on chiasma terminalization was carried out in three bivalents, namely $L_{3}, M_{4}$ and $M_{5}$. All of them can be unequivocally distinguished at diplotene: $\mathrm{L}_{3}$ is the smallest submetacentric, $\mathrm{M}_{4}$ and $\mathrm{M}_{5}$ are the largest autosomal acrocentrics but they differ in their lengths and C-banding patterns. In both bivalents centromeric C-bands are more prominent than the telomeric ones, however these are usually more obvious in $\mathbf{M}_{5}$ bivalents (fig. 1 ). In metaphase I cells $\mathbf{M}_{4}$ and $\mathbf{M}_{4}$ were only distinguished by their length. Some examples of 


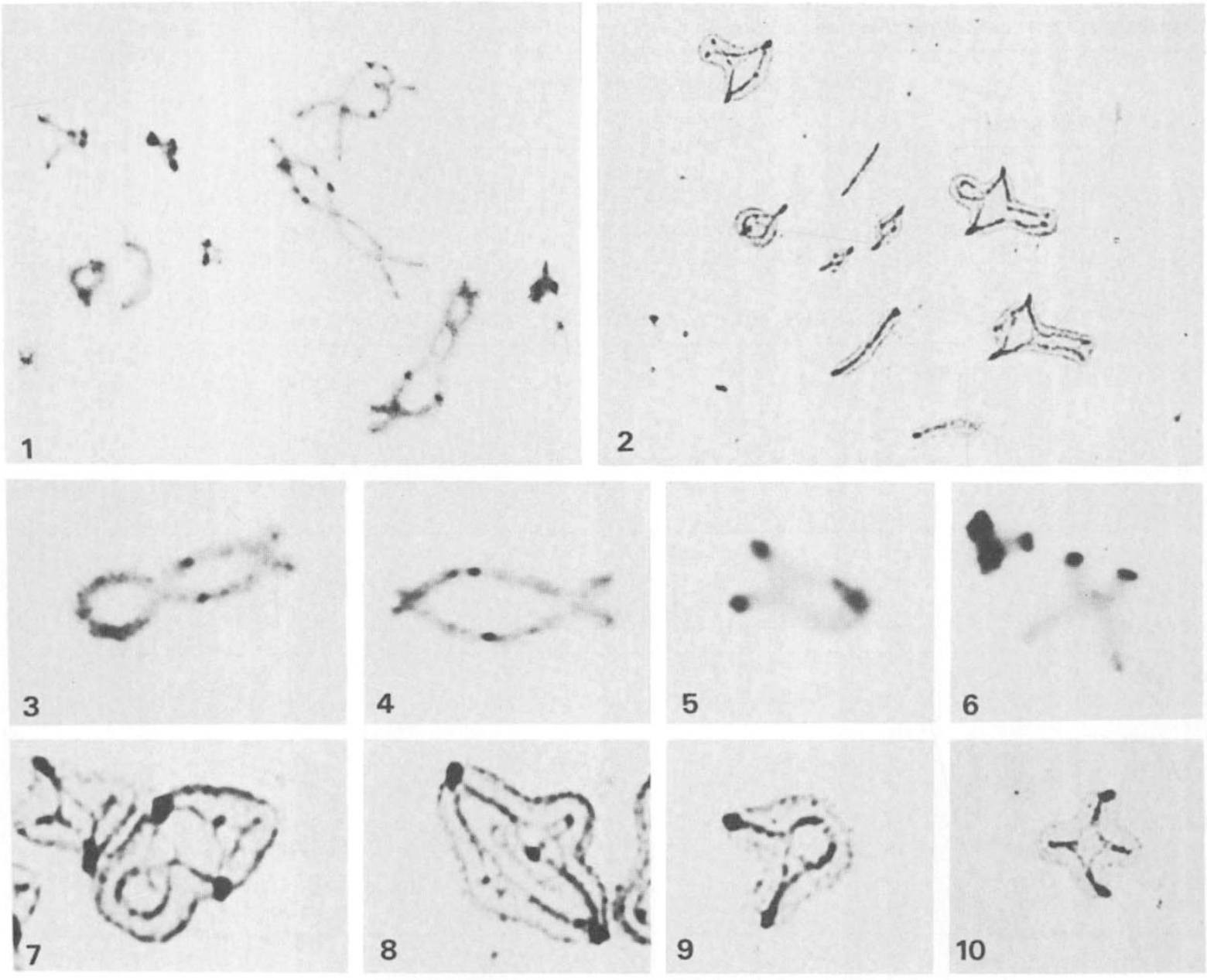

Figure 1. C-banded diplotene cell. Figure 2. Metaphase $I$ cell in which the core-like structure is seen in all bivalents and in the $\mathrm{X}$ chromosome. Figures 3-6. Selected C-banded diplotene bivalents. (3) L3 1:2; (4) L3 1:1; (5) M4/M5 two chiasmata; (6) M4/M5 one chiasma. Figures 7-10. Selected silver stained metaphase I bivalents with similar chiasma frequencies and distributions to those observed in the diplotene bivalents (figs. 3-6).

bivalents at diplotene and metaphase I are shown in figs. $1-10$.

The results shown in table 1 indicate that in all males analyzed there are no significant differences between the mean chiasma frequencies of $\mathrm{L}_{3}, \mathrm{M}_{4}$ and $\mathbf{M}_{5}$ bivalents at diplotene and metaphase I except for $\mathbf{M}_{4}$ bivalent in male Ch.j.3 where the difference observed was probably due to sampling variation. In all cases in which chiasma distributions at diplotene and metaphase I of the same individual could be statistically compared (tables 2-3), no significant differences were found with the single exception of the $\mathrm{M}_{5}$ bivalent class with only one chiasma in male Ch.j.20. However, in this case the observed deviation is due to an excess of chiasmata in metaphase I bivalents in the interval close to the centromere. If terminalization takes place one would expect the opposite situation, that is, an excess of chiasmata in the interval near the telomere. In those cases in which statistical comparisons could not be made because of the low number of chiasmata observed in a given interval, a similarity in chiasma distributions was also found. It is noteworthy that chiasma distributions observed in the bivalents analyzed here were similar to those described for similar bivalents in other truxaline grasshoppers (Southern, 1967).

All results obtained in this work indicate that in the grasshopper $C$. jucundus there is no evidence of chiasma terminalization. 
Table 1 Comparisons between the mean chiasma frequencies of $\mathrm{L}_{3}, \mathrm{M}_{4}$ and $\mathrm{M}_{5}$ bivalents at diplotene (DP) and metaphase I (MI) cells of the four males analysed

\begin{tabular}{|c|c|c|c|c|c|}
\hline \multirow[b]{2}{*}{ Bivalent } & \multirow[b]{2}{*}{ Meiotic stage } & \multicolumn{4}{|l|}{ Individual } \\
\hline & & Ch.j.6 & Ch.j. 8 & Ch.j.3 & Ch.j.20 \\
\hline $\mathrm{L}_{3}$ & $\begin{array}{l}\text { DP } \\
\text { MI }\end{array}$ & $\begin{array}{l}2.76 t=1.27 \\
2.67 \mathrm{df}=169\end{array}$ & $\begin{array}{l}2.8 t=0.26 \\
2 \cdot 81 \mathrm{df}=188\end{array}$ & $\begin{array}{l}2.76 t=0.71 \\
2.78 \mathrm{df}=247\end{array}$ & $\begin{array}{l}2.79 t=0.13 \\
2.78 \mathrm{df}=311\end{array}$ \\
\hline $\mathrm{M}_{4}$ & $\begin{array}{l}\text { DP } \\
\text { MI }\end{array}$ & $\begin{array}{l}1.63 t=0.7 \\
1.58 \mathrm{df}=182\end{array}$ & $\begin{array}{l}1.75 t=0.81 \\
1.71 \mathrm{df}=241\end{array}$ & $\begin{array}{l}1.63 t=2 \cdot 19^{*} \\
1.49 \mathrm{df}=158\end{array}$ & $\begin{array}{l}1.81 \quad t=1.33 \\
1.75 \mathrm{df}=386\end{array}$ \\
\hline $\mathrm{M}_{5}$ & $\begin{array}{l}\text { DP } \\
\text { MI }\end{array}$ & $\begin{array}{l}1.39 t=1 \cdot 23 \\
1.48 \mathrm{df}=179\end{array}$ & $\begin{array}{l}1 \cdot 39 t=1.88 \\
1.27 \mathrm{df}=235\end{array}$ & $\begin{array}{l}1 \cdot 18 t=1 \cdot 2 \\
1 \cdot 24 \mathrm{df}=264\end{array}$ & $\begin{array}{l}1.67 t=1.46 \\
1.6 \mathrm{df}=380\end{array}$ \\
\hline
\end{tabular}

* Significant at the 5 per cent level.

Table 2 Chiasma distributions within the $\mathrm{L}_{3}$ bivalent at diplotene (DP) and metaphase I (MI) cells in the four males analyzed. Two bivalent classes $(1: 1$ and $1: 2)$ have been considered, in the former the bivalent was divided into six intervals whereas in the latter it was divided into eight intervals

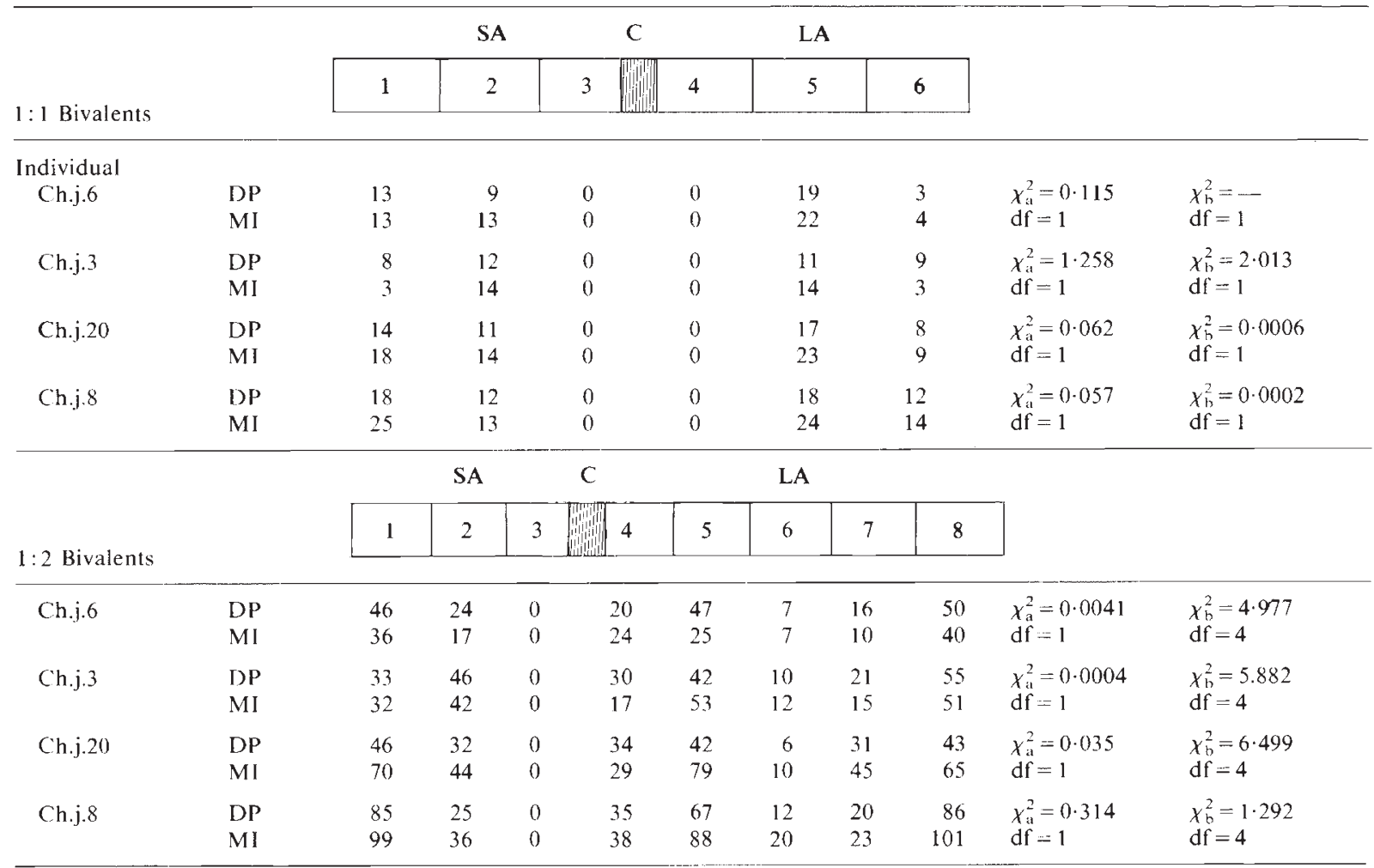

$\mathrm{SA}=$ short $\mathrm{arm}, \mathrm{LA}=$ long $\mathrm{arm}$ and $\mathrm{C}=$ centromere.

No significant differences were found in the contingency $\chi^{2}$ tests. $\chi_{\mathrm{it}}^{2}$ and $\chi_{\mathrm{b}}^{2}$ correspond to the short arm and long arm respectively.

\section{DISCUSSION}

Following Darlington's hypothesis, earlier approaches to studying chiasma terminalization consisted of comparisons of chiasma frequencies and distributions at different meiotic stages. This type of analysis, rather similar to the one employed here, has been considered an indirect method (Jones, 1987) since the number of chiasmata in diplotene bivalents may be overestimated due to the existence of relational twists between homologous chromosomes that could be mistaken 
Table 3 Chiasma distributions within the $M_{4}$ and $M_{5}$ bivalents at diplotene (DP) and metaphase I (MI) cells in the four males analyzed. Two bivalent classes with one and two chiasmata have been considered, in the former both bivalents were divided in three intervals whereas in the latter they were in five $\left(M_{4}\right.$ bivalent $)$ and four $\left(M_{5}\right.$ bivalent $)$ intervals respectively

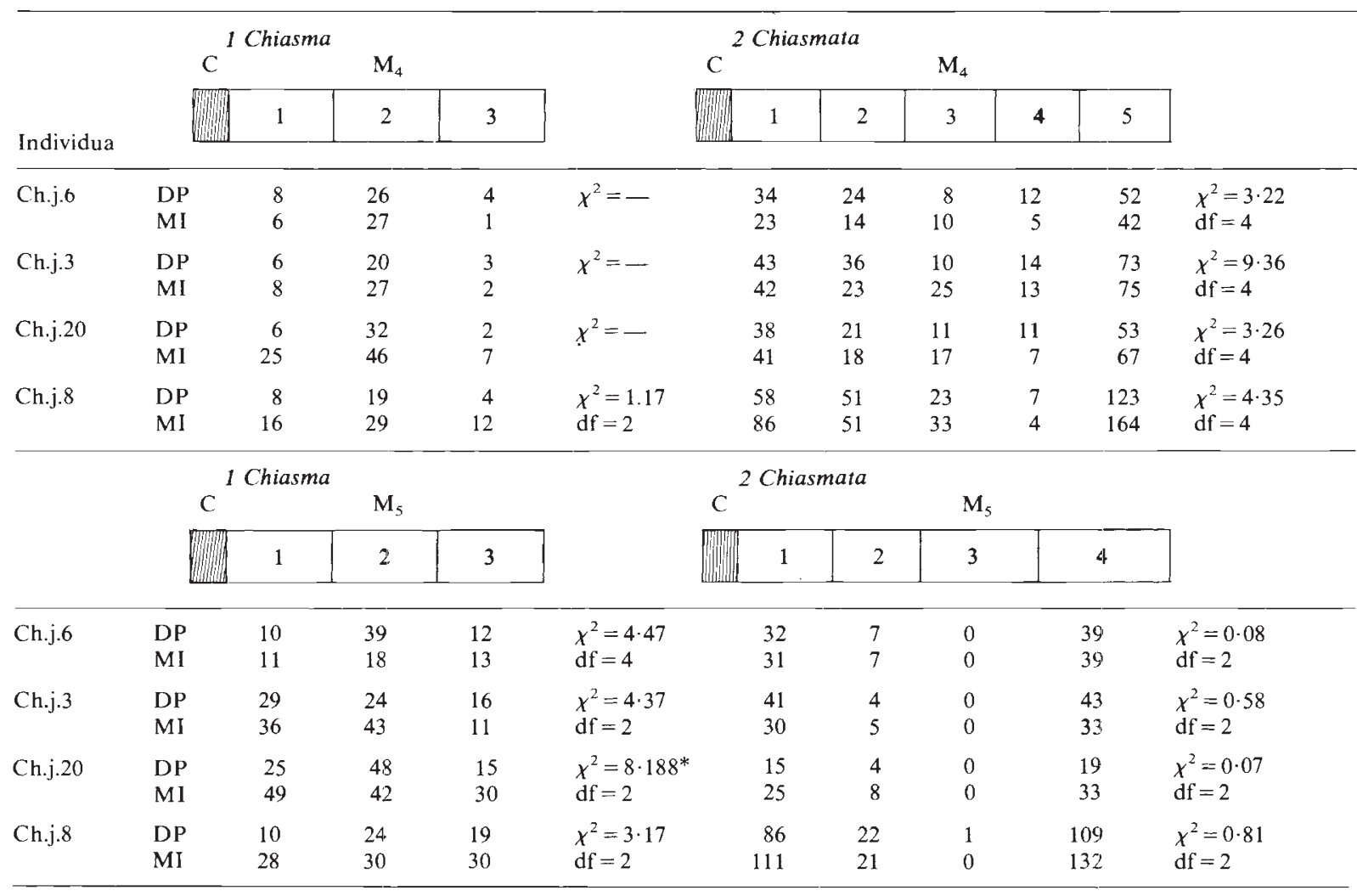

$\mathrm{C}=$ centromere.

* Significant at the 5 per cent level.

for true chiasmata. Likewise, apparent reductions in chiasma frequency at diakinesis and metaphase I might be only due to the condensed appearance of bivalents at these stages. Furthermore, variation in cell chiasma frequencies at different meiotic stages might be due to developmental or environmental factors since these cell populations are not identical.

These objections are not applicable to the present work since the statistical comparisons between chiasma frequencies of $L_{3}, M_{4}$ and $M_{5}$ bivalents at diplotene and metaphase I cells within the same individual did not reveal significant differences except in one case (table 1); therefore chiasma loss between different meiotic stages can be excluded. Moreover, in grasshoppers the identification of chiasmata in diplotene bivalents is clear, relational twists can be easily identified and the normal difficulty of accurately scoring chiasmata in con- densed metaphase I bivalents has been circumvented in this study by the application of silver staining. The comparisons of chiasma distributions of a given bivalent $\left(\mathrm{L}_{3}, \mathbf{M}_{4}\right.$ and $\left.\mathrm{M}_{5}\right)$ were made between cells with the same chiasma frequency for such a bivalent and the problem of variation in absolute bivalent length between cells was avoided by considering the position of each chiasma with respect to the centromere as a percentage of the length of the whole bivalent or bivalent arm.

It is noteworthy that in bivalents with nonterminal chiasmata the core-like structures visualized after silver staining do not appear to reach the ends of metaphase I chromosomes (figs. 2, 7, 8 and 10) whereas in bivalents with terminal chiasmata they do (figs. 2, 7 and 9). The causes of this behaviour remain unknown although they may be related to the dispersion of chromatin by the staining treatment. The existence of cores that really 
do not reach the ends of the chromosomes may distort metaphase I chiasma locations but in the direction of more distal chiasmata, however, since chiasma positions do not differ significantly between metaphase I and diplotene (tables 2 and 3) this cannot be an important factor and consequently, the existence of chasma terminalization in C. jucundus was excluded.

Holm and Rasmussen (1983) found in human males an excess of distal chiasmata at diakinesis when compared with recombination nodule/bar distribution observed from pachytene nuclei. They concluded that the existence of chiasma terminalization might explain the results obtained. However, the origin of the spermatocytes analyzed is different since the diakinesis data are observations by Hultén (1974) and it is feasible that chiasma frequencies and distributions in different males may be different as occurs in many organisms. Nevertheless, Laurie et al., (1981) did not find differences when they compared chiasma distributions within chromosomes 1,2 and 9 in seven human males. On the other hand good correlations between recombination nodules or bars and chiasma data have been found in man (Solari, 1980), Allium fistulosum (Albini and Jones, 1984) and Choealtis conspersa (Bernelot-Moens and Moens, 1986).

Von Wettstein et al., (1984) proposed that chiasma terminalization is not a general phenomenon and that it depends on the behaviour of the synaptonemal complex after pachytene. For instance they propose that the absence of terminalization in Locusta migratoria (Tease and Jones, 1978) could be related to the presence of synaptonemal complex components between the sister chromatids of bivalents until anaphase I. Chiasma terminalization would be present in those species in which such synaptonemal complex components disappear during diplotene or diakinesis. This hypothesis was extended to Melanoplus species. In $M$. femur-rubrum an excess of distal chiasmata at metaphase I (Hearne and Huskins, 1935) was interpreted as proof of chiasma movement while in $M$. differentialis a full elimination of the synaptonemal complex was observed at diakinesis (Solari and Counce, 1977). However there are no observations on the synaptonemal complex evolution during different meiotic stages in the former species whereas in the latter chiasma distributions at diplotene and metaphase I are unknown. Further investigation of this topic is necessary and, in particular, knowledge of the behaviour of synaptonemal complex in the species studied here, C. jucundus would be relevant.
Acknowledgements We are very grateful to Dr Gareth Jones for critical discussion and review of this manuscript.

\section{REFERENCES}

ALBINI, S. M. ANI JONES, G. H. 1984. Synaptonemal-complex associated centromeres and recombination nodules in plant meiocytes prepared by an improved surface-spreading technique. Exp. Cell Res., 155, 588-592.

ALLEN, J. W. 1979. BrdU-Dye characterization of late replication and meiotic recombination in Armenian hamster germ cells. Chromosoma, 74, 189-207.

BERNELOT-MOENS, C. AND MOENS, P. B. 1986. Recombination nodules and chiasma localization in two Orthoptera. Chromosoma, 93, 220-226.

DARLINGTON, C. D. 1929. Chromosome behaviour and structural hybridity in the Tradescantiae. J. Genet., 21, 221-264.

FOX, D. F. 1973. The control of chiasma distribution in the locust Schistocerca gregaria (Forskal). Chromosoma, 43, 289-328

HEARNE, E. M. AND HUSKINS, C. L. 1935. Chromosome pairing in Melanoplus femur-rubrum. Cytologia, 6, 123-147.

HOL.M, P. B. AND RASMUSSEN, S. W. 1983. Human meiosis. VII. Chiasma formation in human spermatocytes. Carlesberg Res. Commun., 48, 415-156.

HUlteN, M. 1974. Chiasma distribution at diakinesis in the normal human male. Hereditas, 76, 55-78.

IMAI, H. T. AND MORIWAKI. K. 1982. A re-examination of chiasma terminalization and chiasma frequency in male mice. Chromosoma, 85, 439-452.

JONES, G. H. 1977. A test for early terminalization of chiasmata in diplotene spermatocytes of Schistocerca gregaria. Chromosoma, 63, 287-294.

JONES, (3. H. 1978. Giemsa C-banding of rye meiotic chromosomes and the nature of "terminal" chiasmata. Chromosoma, 66, 45-57.

JONES, G. H. 1984. The control of chiasma distribution. In Evans, C. W. and Dickinson, H. G. (eds), Controlling Events in Meiosis. The Company of Biologists Ltd., Cambridge, pp. 293-320.

JoNrs, G. H. 1987. Chiasmata. In Moens, P. B. (ed.), Meiosis, Academic Press, pp 213-244.

KANDA, N. AND KATO, H. 1980. Analysis of crossing over in mouse meiotic cells by BrdU labelling technique. Chromosoma, 78, 113-121.

LAURIE, D. A. AND JONF.S, G. H. 1981. Inter-individual variation in chiasma distribution in Chorthippus brunneus (Orthoptera: Acrididae). Heredity, 47, 409-416.

LAURiE, D. A., HULten, M. AND JONES, G. H. 1981. Chiasma frequency and distribution in a sample of human males: chromosomes 1, 2 and 9. Cytogenet. Cell Genet., 31, 153166.

I.OIDL, J. 1979. C-Band proximity of chiasmata and absence of terminalization in Allium flavum (Liliaceae). Chromosoma, 73, 45-51.

I.OIDL. J. 1987. Heterochromatin and differential chromosoma staining in meiosis. Biol. Zentralbl., 106, 641-662.

MACiUIRE, M. P. 1979. Direct cytological evidence for true terminalization of chiasmata in maize. Chromosoma, 71, 283-287.

MAGUIRE, M. P. 1981. Chiasma maintenance and terminalization across a homoeologous bivalent segment. Chromosoma, 82, 107-112.

MASCARELLO, I. T. 1980. Meiotic chromosomes of antelope squirrels. Cytogenet. Cell Genet., 26, 104-107. 
MAUDLIN, I. AND EVANS, E. P. 1980. Chiasma distribution in mouse oocytes during diakinesis. Chromosome, 80, 49-56.

ORELlanA, J. AND GIRALDEZ, R. 1981. Metaphase I bound arms and crossing-over frequency in rye 1 . Open pollinated varieties. Chromosoma, 84, 439-449.

POlANi, P. E., CROLlA, J. A., SElles, H. J. AND MOIR, F. 1979. Meiotic crossing-over exchange in the female mouse visualised by BrdU substitution. Nature, 278, 348-349.

RUFAS, J. S., ESPONDA, P. AND GOSALVEZ, J. 1985. NOR and nucleolus in the spermatogenesis of Acridoid grasshoppers. Genetica, 66, 139-144

SANTOS, J. L. AND GIRALDEZ, R. 1978. The effect of C-heterochromatin on chiasma terminalization in Chorthippus biguttulus L. (Acrididae, Orthoptera). Chromosoma, 70, 59-66.

SANTOS, J. L. 1980. Variación de la heterocromatina constitutiva en el cariotipo de los Acridoidea y su efecto en el comportamiento cromosómico en meiosis. Tesis Doctoral. Universidad Complutense de Madrid.
SANTOS, J. L., CiPRÉS, G. AND LACAdenA, J. R. 1987. Metaphase I chiasmata in silver-stained cores of bivalents in grasshopper spermatocytes. Genome, 29, 235-238.

SOLARI, A. J. AND COUNCE, S. C. 1977. Synaptonemal complex karyotyping in Melanoplus differentialis. J. Cell Sci., 26, 229-250

SOLARI, A. J. 1980. Synaptonemal complexes and associated structures in microspread human spermatocytes. Chromosoma, 81, 315-337.

SOUTHERN, D. 1. 1967. Chiasma distribution in Truxaline grasshoppers. Chromosoma, 22, 164-191.

TEASE, C. AND JONES, G. H. 1978. Analysis of exchanges in differentially stained metiotic chromosomes of Locusta migratoria after BrdU-substitution and FPG staining. Chromosoma, 69, 163-178.

WETTSTEIN, D. VON, RASMUSSEN, S. W. AND HOLM, P. B. 1984. The synaptonemal complex in genetic segregation. Ann. Rev. Genet., 18, 331-413. 